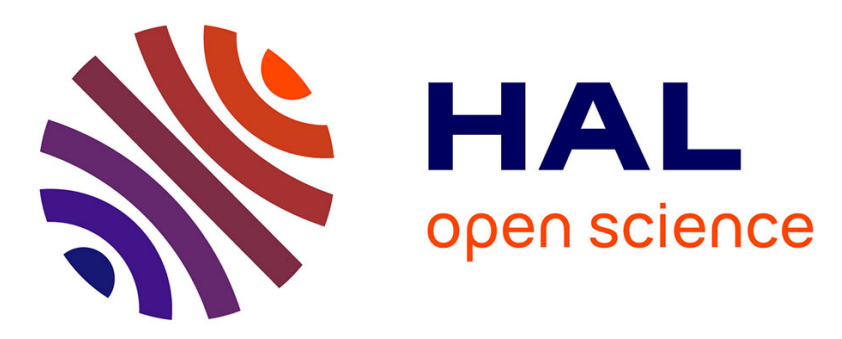

\title{
Collaborative plant breeding for organic agricultural systems in developed countries
}

Julie Dawson, Pierre Rivière, Jean-François Berthellot, Florent Mercier, Patrick de Kochko, Nathalie Galic, Sophie Pin, Estelle Serpolay, Mathieu

Thomas, Simon Giuliano, et al.

\section{To cite this version:}

Julie Dawson, Pierre Rivière, Jean-François Berthellot, Florent Mercier, Patrick de Kochko, et al.. Collaborative plant breeding for organic agricultural systems in developed countries. Sustainability, 2011, 3 (8), pp.1206-1223. 10.3390/su3081206 . hal-01458584

\section{HAL Id: hal-01458584 https://hal.science/hal-01458584}

Submitted on 29 May 2020

HAL is a multi-disciplinary open access archive for the deposit and dissemination of scientific research documents, whether they are published or not. The documents may come from teaching and research institutions in France or abroad, or from public or private research centers.
L'archive ouverte pluridisciplinaire HAL, est destinée au dépôt et à la diffusion de documents scientifiques de niveau recherche, publiés ou non, émanant des établissements d'enseignement et de recherche français ou étrangers, des laboratoires publics ou privés. 
Article

\title{
Collaborative Plant Breeding for Organic Agricultural Systems in Developed Countries
}

\author{
Julie C. Dawson ${ }^{1,2, \star}$, Pierre Rivière ${ }^{1}$, Jean-François Berthellot ${ }^{3}$, Florent Mercier ${ }^{3}$, \\ Patrick de Kochko ${ }^{3}$, Nathalie Galic ${ }^{1}$, Sophie Pin ${ }^{1}$, Estelle Serpolay ${ }^{4}$, Mathieu Thomas ${ }^{1}$, \\ Simon Giuliano ${ }^{5}$ and Isabelle Goldringer ${ }^{1}$ \\ ${ }^{1}$ UMR de Génétique Vegetale, Ferme du Moulon, 91190 Gif-sur-Yvette, France; \\ E-Mails: pierre.riviere@moulon.inra.fr (P.R.); galic@moulon.inra.fr (N.G.); \\ jouanne@moulon.inra.fr (S.P.); thomas@moulon.inra.fr (M.T.); isa@ moulon.inra.fr (I.G.) \\ 2 current address 422 Bradfield Hall, Department of Plant Breeding and Genetics, Cornell University, \\ Ithaca, NY 14853, USA \\ ${ }^{3}$ Réseau Semences Paysannes Cazalens, 81600 Brens, France; \\ E-Mails: contact@ semencespaysannes.org (J-F.B., F.M.); patrick@ semencespaysannes.org (P.K.) \\ ${ }^{4}$ INRA SAD Paysage, 65 rue de St. Brieuc, 35042 Rennes, France; \\ E-Mail: estelle.serpolay@ rennes.inra.fr (E.S.) \\ ${ }^{5}$ Ecole d'Ingénieurs de Purpan, 75 voie du Toec, 31076 Toulouse, France; \\ E-Mail: simon.giuliano@purpan.fr (S.G.)
}

* Author to whom correspondence should be addressed; E-Mail: jcd11@ cornell.edu;

Tel.: 607-255-8092 Fax: 607-255-6683.

Received: 31 May 2011; in revised form: 19 July 2011 / Accepted: 27 July 2011 /

Published: 10 August 2011

\begin{abstract}
Because organic systems present complex environmental stress, plant breeders may either target very focused regions for different varieties, or create heterogeneous populations which can then evolve specific adaptation through on-farm cultivation and selection. This often leads to participatory plant breeding (PPB) strategies which take advantage of the specific knowledge of farmers. Participatory selection requires increased commitment and engagement on the part of the farmers and researchers. Projects may begin as researcher initiatives with farmer participation or farmer initiatives with researcher participation and over time evolve into true collaborations. These projects are difficult to plan in advance because by nature they change to respond to the priorities and interests of the collaborators. Projects need to provide relevant information and analysis in a time-frame that
\end{abstract}


is meaningful for farmers, while remaining scientifically rigorous and innovative. This paper presents two specific studies: the first was a researcher-designed experiment that assessed the potential adaptation of landraces to organic systems through on-farm cultivation and farmer selection. The second is a farmer-led plant breeding project to select bread wheat for organic systems in France. Over the course of these two projects, many discussions among farmers, researchers and farmers associations led to the development of methods that fit the objectives of those involved. This type of project is no longer researcher-led or farmer-led but instead an equal collaboration. Results from the two research projects and the strategy developed for an ongoing collaborative plant breeding project are discussed.

Keywords: farmer varieties; genetic diversity; in situ conservation; organic agriculture; participatory plant breeding

\section{Introduction}

The regulatory system in many countries, particularly in the European Union, restricts the varieties available to farmers to those registered in an official catalogue (National or European). In the EU, to be commercialized, a variety has to be registered in the European catalogue and meet evaluation criteria including "distinctiveness, uniformity and stability" (DUS). Further regulations for variety registration vary by country but usually include "value for cultivation and use" standards that measure agronomic performance and technical end-use quality in conventional systems. This has resulted in a lack of suitable varieties available to organic farmers, since most modern varieties are developed for and tested in high-input conventional cropping systems. Thus, many farmers using organic and low-input methods are unable to find a variety in the catalogue that is adapted to their agricultural environment. The vast majority (over 95\%) of varieties used in organic agriculture were initially bred for conventional systems [1].

Due to the expense of registering a variety and the limited markets for organic seed, private-sector breeders must add organic breeding activities to existing conventional activities, and in general cannot spend more than $10 \%$ of their breeding investment on organic systems [2]. Because conventional systems can be buffered by inputs, the natural environmental variability encountered by modern varieties is generally limited, which makes it possible to breed varieties with apparent broad adaptation. This reduces the need for genetic diversity in commercial varieties [3] but these varieties are only superior in a narrow range of production environments where growing conditions are standardized and stress is minimized [4]. Many authors have pointed to a need for greater diversity in agriculture [1,3,5-12]. Due to greater heterogeneity of environmental conditions (both spatial and temporal) in organic systems, there is a particular need to increase genetic diversity on organic farms [13-18].

If the target environments are too different to select a single variety or population that has acceptable performance everywhere, breeders may target very focused regions for different varieties or heterogeneous populations that may then evolve specific adaptation. When varieties have different performance relative to each other when changing environments, variety-by-environment interactions, 
or more commonly, genotype by environment $(\mathrm{G} \times \mathrm{E})$ are present. In this case, an analysis of $\mathrm{G} \times \mathrm{E}$ is a method of choosing the best variety or population for each target environment [4]. Usually, significant $G$ $\times$ E interactions imply that selection needs to be conducted in the target environment. Where this direct selection in the target environment is important, decentralization of the selection process is necessary and this often leads to participatory selection $[19,20]$ because of the need to reduce differences between selection sites and the target environments. Decentralized selection on regional research stations may still not be representative of on-farm environments and management. Farmer participation brings more than just more representative testing locations, as farmers have in-depth knowledge of environmental conditions and plant traits that are adaptive under their conditions. The positive use of $\mathrm{G} \times \mathrm{E}$ to develop locally-adapted varieties through decentralized selection and participatory breeding has been proposed as a solution to breeding for organic and low-input systems. The basis for many participatory plant breeding projects lies in the use of the genetic diversity present in farmer varieties and in farmers' specific knowledge and evaluation of varietal traits of importance in their agricultural environment. The need for specific traits (both agronomic and quality) for different environments and management practices is currently not considered in the official varietal registration process. In developed countries, interest in on-farm breeding and conservation has been primarily from organic and low-input farmers because they face many challenges not present in conventional systems, including more heterogeneous environmental conditions, the absence of adapted varieties, and a lack of interest by the commercial seed sector in producing varieties for these systems $[15,18]$.

Farmers interested in on-farm breeding often look for more diverse varieties because they want these varieties to be able to evolve specific adaptation to their conditions, and because genetic heterogeneity may buffer crop responses to unpredictable environmental conditions. The agronomic benefits of diversity include improved durability of disease resistance and reduction of disease severity [16,21] and greater buffering capacity of heterogeneous populations [22,23]. In heterogeneous populations, phenotypic stability may arise from genetic diversity that allows the flexible expression of component traits that lead to higher stability for complex traits such as yield and quality. In addition to contributing to the development of well-adapted varieties, the conservation of genetic diversity within varieties is also important to maintain the adaptive potential of these varieties. Contrasted selection pressures over multiple farms will preserve the greatest level of diversity at the meta-population level (i.e., considering all the farms together), even if each population loses a portion of its initial diversity in the process of selection for local adaptation [24-28]. Selection and conservation objectives benefit from the ability to evaluate and use the widest range of genetic diversity available.

Because of the benefits drawn from diversity under organic conditions, organic farmers in developed countries have been key in the development of seed exchange and seed saving organizations [29]. The work presented in this paper was possible because of the engagement and activities of the Réseau Semences Paysannes (RSP, Farmers' seed network), a farmers' association dedicated to the conservation, cultivation and exchange of diverse varieties. Farmers involved in this network grow historic varieties and landraces because they are more suitable for their management practices and because of superior quality characteristics for on-farm processing and direct sales to consumers. They also have a strong commitment to preserving biodiversity, with some farmers growing over 200 different varieties in small $\left(5 \mathrm{~m}^{2}\right)$ plots and continuously experimenting with new varieties from different genebanks and 
collections. Demeulenaere et al. [5] showed that a small group of farmers growing these types of populations can make a significant contribution to the conservation of genetic diversity when compared to the diversity present in specific genebank accessions. On-farm cultivation of these diverse varieties is an effective method of in situ conservation which also conserves the evolutionary process [30-34].

In this paper, we first present results from an experiment on the evolution of wheat landraces cultivated on-farm over 3 years, with farmer mass selection in the final year. This researcher-led project was designed to address the need for more information on how on-farm selection and management affects the diversity of cultivated species and how these practices can be optimized for both the conservation of important genetic resources and the development of well-adapted varieties. Second, we present results from a farmer-led plant breeding project that was initiated by farmers in the RSP to create locally adapted varieties and increase farmer autonomy in terms of varietal choice and seed production. In the first case farmers participated in a researcher-led project and in the second, researchers participated in a farmer-led project. Finally, the process of developing a collaborative plant breeding program for organic agriculture is presented in the last two sections of the discussion, including lessons learned from our current work and their implications for its future direction. It is challenging to develop sustainable collaborations with research strategies that work for scientists and farmers, and the role of the RSP farmers' association was critical in creating a successful model. We consider collaborative plant breeding to be a method where interested parties participate equally in the development, implementation and evaluation of a plant breeding program. In our case, this included farmers who also mill their grain and have on-farm bakeries, farmers' associations and public-sector researchers. We hope that our experience will prove useful to other project teams working to do applied on-farm research and plant breeding.

\section{Materials and Methods}

Two on-farm studies of farmer varieties of bread wheat in organic systems were conducted from 2006 to 2010. The first project studied variety evolution and farmer mass selection in wheat populations within the framework of the European project Farm Seed Opportunities (FSO), designed principally to study the evolution, diversity and adaptation of non-conventional varieties, such as landraces, historic varieties and varietal mixtures, referred to as farmer varieties hereafter. The second is an ongoing project between the RSP and researchers from the Institut National de la Recherche Agronomique (INRA). This project is creating new populations by crossing wheat landraces and other public varieties and is referred to as the Croisements $d u$ Roc after the farm where the crosses were made.

\subsection{Farm Seed Opportunities}

Eight farmer varieties of bread wheat and two modern varieties were studied from 2006 to 2009 as part of the FSO project. These varieties were grown for 2 years on organic farms, 4 in France, 2 in Italy and 2 in the Netherlands. In the 3rd year, 2008-2009, replicated trials on each farm compared a sample of the variety from the originating farmer (original version) to the version grown for the two previous years on their farm (3rd generation version)(see Figure 1). An additional step was added in 2009 for three farmers who chose to participate to measure the effects of farmer mass selection. These farmers first gave their feedback on the varieties studied in order to choose five of these varieties for the selection 
protocol. The varieties chosen represent different genetic structures and included Piave (PI), a landrace from NE Italy; Rouge de Bordeaux (RB), a historic variety from SW France; Redon (RD), a mixture of landraces of the same name from western France; Renan (RN), a modern variety considered to be the reference for organic agriculture; and Zonnehoeve $(\mathrm{ZH})$, a mixture of two modern varieties from the 1990s, grown as a mixture for 15 years on an organic farm in the Netherlands (see Serpolay et al. [35] for more details on the varieties).

Figure 1. FSO project design for each variety $i$ farm $j$. $\mathrm{V}_{i o}$ indicates seed harvested from the variety $i$ in its region of origin. All varieties were cultivated on each farm from 2006-2009.

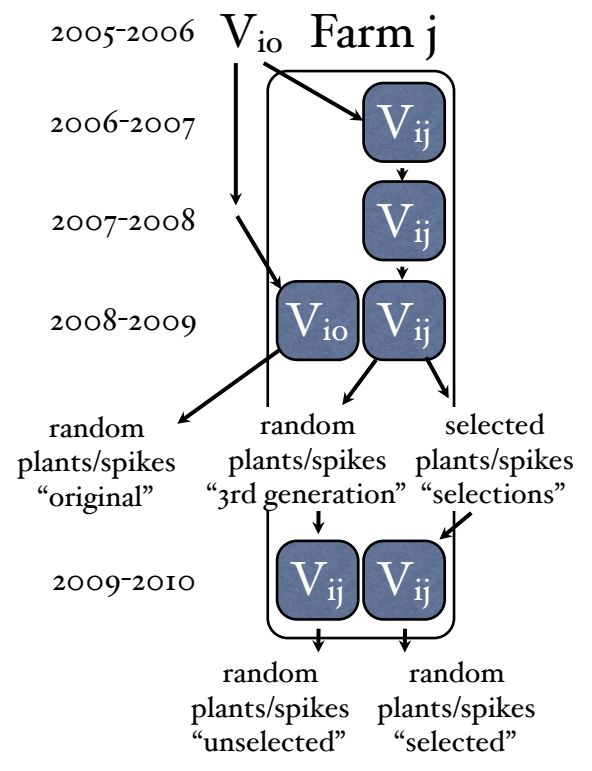

Before harvest, each of the farmers were asked to select 20 spikes (from different plants) in the 2 replicates of the 3rd generation version of each varieties. Phenotypic traits were measured at maturity for these selected individuals and for 20 other individual plants chosen at random from each replicate of the origin and 3rd generation version. These traits included plant height $(\mathrm{PH})$, last leaf-to-spike distance (LLSD), spike length (SL), grain weight per spike (GW/spike), and thousand kernel weight (TKW). LLSD was considered important by farmers based on their observations, because a longer LLSD distances the spike from the canopy and potential foliar disease spores, may reduce humidity around the spike making conditions less favorable to disease development, and may improve grain filling under conditions where leaves no longer photosynthesize due to drought, heat or disease stress. The other individual plant traits were chosen based on the descriptors used for variety registration (which evaluate the distinctiveness, uniformity and stability of varieties), in order to characterize farmer varieties with respect to modern varieties.

The versions were then compared (origin vs. 3rd generation without selection, and selections within the 3rd generation vs 3rd generation without selection) for these phenotypic traits. The analysis of on-farm evolution and selection differentials were done using an ANOVA model: $Y=u+f a r m+r e p(f a r m)+$ variety + version (variety $)+$ farm $*$ variety + farm $*$ version(variety) + error . Tests of differences between versions were done using Tukey's multiple comparison procedure for two cases: (i) between the original and 3rd generation (without conscious selection) versions within each 
farm and variety; and between selections and the 3rd generation (without conscious selection) version within each farm and variety. In 2009-2010, progeny head-rows of selected and non-selected spikes of all four farmers varieties and Renan were grown at the research station of INRA le Moulon. Plots of selected and non-selected progeny of Rouge de Bordeaux (RB), Blés de Redon (RD) and Renan (RN) were grown on one participating farm to analyze the response to selection. Results from the on-farm trial are presented here.

\subsection{Croisements du Roc}

On the initiative of a farmer active in the RSP, a participatory plant breeding project was started in 2005 with researchers from INRA le Moulon. Crosses were made on his farm between different wheat landraces and more recent varieties of interest. The first $\left(\mathrm{F}_{1}\right)$ and second $\left(\mathrm{F}_{2}\right)$ generations of progeny of 90 different families (one family is derived from each cross) were also evaluated on his farm in 2006-2007 and 2007-2008. Selections were made of individual spikes in several of the $\mathrm{F}_{2}$ families. Seed of these spikes was bulked for each family and evaluated side-by-side in the F3 generation with the corresponding unselected bulk at Moulon in 2008-2009. The protocol for plant and spike measurements was the same as that of the FSO project. Analysis was done using an ANOVA model: $Y=u+$ rep + family + version(family) + error for the trial at le Moulon; tests between the selected and non-selected versions within each family were made with Tukeys multiple comparison procedure.

$\mathrm{F}_{2}$ families were harvested in bulk in 2008 on-farm and seed was distributed to 14 additional farmers in the autumn of 2008 for the evaluation of the $\mathrm{F}_{3}$ generation on their farms. Management of on-farm trials was the responsibility of the farmers, and researchers made phenotypic measurements on 25 plants and spikes per $\mathrm{F}_{3}$ family on each farm at maturity. This was the first year of diffusion of progeny from these crosses within the farmer seed network, and was an experimental year to see if farmers were interested and how the network could enhance the use of results from these types of trials. In the 2009-2010 year, all but two farmers continued their populations for the $\mathrm{F}_{4}$ generation using seed they harvested from $\mathrm{F}_{3}$ plants in 2009, and an additional 12 farmers joined the project, primarily cultivating $\mathrm{F}_{3}$ populations from the remaining seed of the 2008 harvest. In addition to on-farm evaluation, crosses were made in the spring of 2010 and 2011 to start new populations. These crosses were made between parents chosen by farmers for their particular environments, and a workshop on creating new populations through crossing different varieties was held at le Moulon in February 2010.

In 2010-2011, the on-farm trials have been substantially modified to better meet the needs of scientists and farmers. Trials are now structured into regional platforms with surrounding satellite trials where each farmer tests the most promising populations for their farm and a larger number of populations are tested on a central farm for each region. This network of on-farm trials will permit an analysis over multiple locations and years for each family and exchanges among participating farmers in order to provide quantitative and qualitative information on the different families to aid in making selection decisions. This new strategy is the result of farmers and researchers learning during the first years of the Croisements $d u$ Roc project and during the FSO project and the lessons taken from these two experiences and new methods for collaborative plant breeding are described at the end of the discussion. 


\section{Results}

\subsection{Farm Seed Opportunities}

There were often similar levels of intra-varietal variability between farmer and modern varieties, indicating that the strong selection for genetic homogeneity to meet regulatory criteria had little impact on the phenotypic variability of certain traits when assessed on organic farms [35]. This could be due to high levels of micro-environmental variation within plots or residual genetic variation that is not expressed in conventional trials. Several farmer varieties had high values of traits related to productivity outside their region of origin, which underlines the need for experimentation and exchange across regions with diverse material in order to find and develop appropriate varieties for organic systems [35].

In general there were fewer and more moderate significant differences due to on-farm evolution without selection than there were significant selection differentials (see Figure 2). Natural selection increased plant height (PH) twice and decreased it 3 times, with non-significant differences 10 times, while selection differentials for $\mathrm{PH}$ were significant for all varieties and all farms except for $\mathrm{ZH}$ at farm $\mathrm{HF}$ and was always in the direction of increasing plant height. Natural selection decreased the LLSD twice and had no other significant differences. LLSD was more variable, with fewer significant selection differentials, and significant changes in both directions. Natural selection increased GW/spike twice and decreased it 6 times, with 7 non-significant differences. GW/spike always had a significant positive selection differential except for RD at farm HF. KN/spike (not shown) presented similar results to GW/spike. Natural selection increased TKW once, decreased it 4 times, with 10 non-significant differences. TKW also had significant positive selection differentials except for RB at farms GC and HF and RN at farm HF where it was negative, and for $\mathrm{ZH}$ at farm GC where it was not significant.

Figure 3 shows selection differentials for PH and GW/Spike in 2009 for RB, RD, and RN selected by FM and the selection response for the same populations grown in 2010 at FM. KN/Spike showed the same pattern as GW/Spike. Selection differentials were positive for all three varieties for PH, KN/Spike and GW/Spike, but only RB showed significant positive responses to selection for these traits. There were no significant responses for LLSD or TKW.

\subsection{Croisements du Roc}

Significant quantitative responses to selection were found in many $\mathrm{F}_{3}$ families at Le Moulon. Table 1 shows significant differences between $\mathrm{F}_{3}$ progeny of selected and non-selected $\mathrm{F}_{2}$ spikes. There were significant responses to selection for many families, a few are shown as examples. There were also 9 of 36 families with no significant changes for any trait measured and several which only showed a significant response to selection for a few traits. There were more significant differences for $\mathrm{PH}$ and LLSD, while GW and TKW had fewer families that showed a significant response to selection. However, $\mathrm{PH}$ and LLSD changed in both directions while the change in GW and TKW was always positive.

For the $\mathrm{F}_{3}$ and $\mathrm{F}_{4}$ populations, it was possible to qualitatively differentiate among families grown at the same farm, and there were usually one or two families that stood out to the farmer as being particularly interesting in the first year. Farmers chose to either continue with all families for the second year or to discard certain families and add new ones for the 2009-2010 growing season. Evaluations from 2010 
Figure 2. Tests of significant differences by variety and farm due to on-farm evolution over 3 years without human selection and tests of significance for selection differentials.

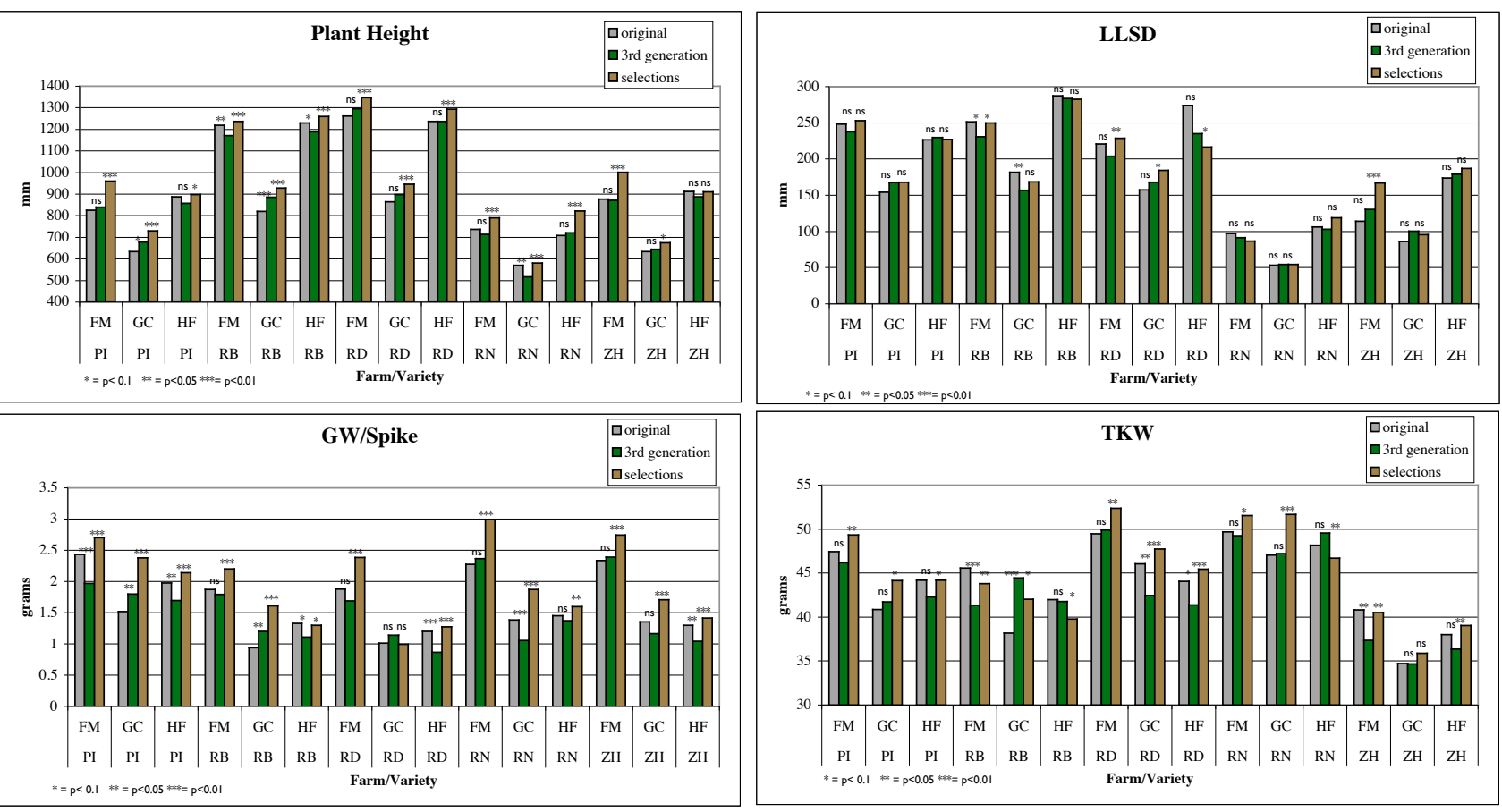

Figure 3. Selection differentials (2009) and response to selection (2010) for Rouge de Bordeaux (RB), Bles de Redon (RD) and Renan (RN) grown on the farm of FM. Significance levels are: $* * p<0.01, * * * p<0.001$.
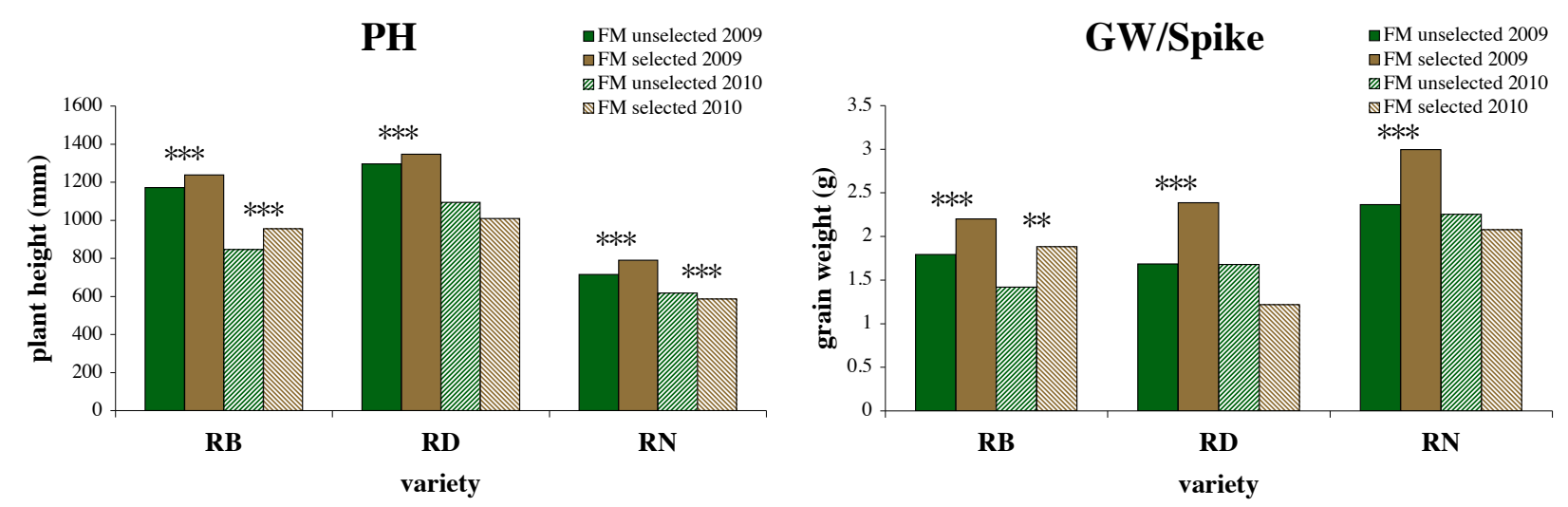

were used to decide on which populations to keep on each farm for 2010-2011. In 2010-2011 a new methodology was adopted by the selection network, described in the discussion section.

\section{Discussion}

\subsection{Selection within Farmer Varieties}

Traits such as PH are very easy to see in the field and every farmer chose plants that were taller than the average for the plot, but that had not lodged. The majority of organic farmers involved in this network state that they would like varieties that are vigorous and tolerant of weed pressure early in the growing 
Table 1. Examples of families with significant changes among $\mathrm{F}_{3}$ progeny from selected and non-selected spikes in the $\mathrm{F}_{2}$ generation evaluated at the research station of Le Moulon.

\begin{tabular}{cccccccccc}
\hline & \multicolumn{2}{c}{ PH } & \multicolumn{2}{c}{ LLSD } & \multicolumn{2}{c}{ GW/Spike } & \multicolumn{2}{c}{ TKW } \\
\hline Family & P-value & Change & P-value & Change & P-value & Change & P-value & Change \\
\hline 24 & 0.0187 & - & 0.4038 & $\mathrm{~ns}$ & 0.6568 & $\mathrm{~ns}$ & 0.0021 & + \\
34 & 0.0001 & + & $<.0001$ & + & 0.723 & $\mathrm{~ns}$ & 0.0051 & + \\
42 & 0.0786 & + & 0.0016 & + & 0.5407 & $\mathrm{~ns}$ & 0.602 & $\mathrm{~ns}$ \\
60 & 0.0956 & + & 0.0442 & - & 0.6457 & $\mathrm{~ns}$ & 0.752 & $\mathrm{~ns}$ \\
64 & $<.0001$ & + & 0.0001 & + & 0.0366 & + & 0.3011 & $\mathrm{~ns}$ \\
80 & $<.0001$ & + & 0.0114 & + & 0.0158 & + & 0.0884 & + \\
90 & 0.5706 & $\mathrm{~ns}$ & 0.2792 & $\mathrm{~ns}$ & 0.0014 & + & 0.0005 & +
\end{tabular}

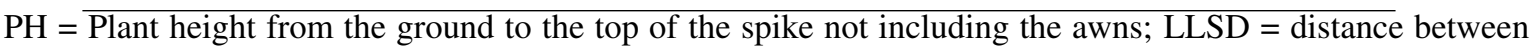
the base of the spike and the flag leaf; SL = length of the spike from the base to the tip not including the awns; GW/Spike = weight of grain per spike; TKW = thousand kernel weight; $\mathrm{P}=$ values for the difference between selected and non-selected progeny within each $\mathrm{F}_{3}$ family using ANOVA and Tukeys mcp. The direction of change from non-selected to selected progeny is given for $p<0.1 ;-$ non-selected $>$ selected, + non-selected $<$ selected, $\mathrm{ns}=p>0.1$.

season but strong enough not to lodge. In contrast, long LLSD is a characteristic sought by farmers but did not have a significant selection differential in most cases. This trait may be more difficult to evaluate in the field or may not be as important as traits such as GW/spike and PH when farmers are making their selections.

$\mathrm{GW} /$ spike seems to be fairly easy to evaluate in the field, as there were almost always significant selection differentials. This trait was not always favored by natural selection, even if we may reasonably hypothesize that it is connected to plant fitness. There may be a trade-off with plant height, where tall plants are favored during the growing season due to competition for light, but those that have heavy spikes have a greater tendency to lodge and be lost at harvest. TKW had a significant selection differential in all but one location for one variety, and was positive in all but 3 cases when it was significant. This is somewhat surprising due to the difficulty of visually assessing the TKW of spikes without looking at the grain.

In the on-farm evaluation of the response to selection, one historic variety, $\mathrm{RB}$, responded positively to selection for $\mathrm{PH}$ and $\mathrm{GW} /$ spike while a landrace population, $\mathrm{RD}$, and the modern variety $\mathrm{RN}$ did not, despite significant selection differentials in 2009. This difference in varietal capacity to respond to selective pressure is in agreement with the farmers observation that RB was one of the varieties that performed very well outside its region of origin, indicating greater adaptability than landraces such as RD. It also corresponds to molecular genetics findings of high levels of internal diversity of farmer-managed populations of RB [5]. In contrast, the particular sample of the landrace RD used for this study was composed by a farmer starting from a small number of spikes selected in accessions from the national genebank, possibly inducing a genetic bottleneck and a reduction of adaptive potential. Ex situ conservation in gene banks may lead to reduced genetic diversity due to genetic drift in small population sizes $[9,36]$. The lack of response to selection in Renan is not surprising as we expected the observed selection differential to be due primarily to micro-environmental factors that led to phenotypic 
differences among plants within a single plot in the selection generation. However, these results must be interpreted with caution as they are only from one location. A common garden experiment with all selections from all varieties and farms at the research station le Moulon is currently being analyzed for more generalizable results on response to selection.

Results from the overall FSO project showed that farmer varieties can be heterogeneous for some traits but homogeneous for others, and can be more or less adaptable depending on the trait and range of environmental conditions. The response to natural selection over three years was variable, with traits changing in both directions or not at all, showing that for certain traits, farmer selection is necessary to maintain or improve certain traits. A strong selection differential was expected for some traits that are observed easily in the field, for other traits such as TKW the presence of a strong selection differential was more surprising. The results for some traits are more complex to interpret, and it is not always clear if the lack of a selection differential or response was due to a lack of genetic diversity for those traits or because the traits used for varietal characterization may not be the most appropriate to measure the effects of on-farm selection when this selection is much more holistic in nature. Molecular genetic studies are in progress on the base populations to determine the levels of genetic variation and the on-farm evolution of both neutral variation and variation linked to hypothesized adaptive traits such as earliness.

Significant responses were found after only one cycle of selection in farmer varieties, but this is dependent on the variety and sufficient genetic diversity needs to be present for selection to have an effect. Since farmer selection is based much more on a global evaluation of the plants and populations, and since this often produces desirable agronomic changes in the field based on the experience of farmers in the RSP over several years, quantitative measures and analysis may be most useful when focused on a small number of traits that are more difficult to evaluate by farmers, such as protein content, or that respond unsatisfactorily to their selection, such as LLSD. Quantitative measures may also be used after selection to monitor these changes from one generation to the next, especially for traits that have negative correlations, or to document and characterize these populations as they evolve.

While the EU directive on conservation varieties is an improvement over existing standards which prohibit the exchange of any variety not registered in the official catalogue, it is fairly restrictive in the types of varieties that can be registered in the special catalogue for conservation varieties. It still includes the distinct, uniform and stable criteria for registration, with slightly relaxed criteria of evaluation. In addition, they are limited to a restricted zone of origin and percentage of the area cultivated to that species and to limited quantities for commercial use [37]. The new directive therefore does not include the range of farmer varieties currently of interest in organic systems, and may not be adequate for some types of on-farm conservation and plant breeding activities, especially those conducted by established farmers seed groups, which rely on a broad network seed exchanges to maintain and enhance diversity and agronomic performance.

\subsection{Response to Selection in Early Generations}

The response to selection in early generations that was measured at Le Moulon was of interest to researchers and farmers because it allowed us to evaluate different selection strategies, or example, deciding the generation at which individual spike selection within segregating population might be efficiently introduced, or the number of years to observe a bulk population before selecting among 
bulks. There were many significant changes when comparing $\mathrm{F}_{3}$ progeny from selected and unselected $\mathrm{F}_{2}$ generation spikes. Some families had more significant changes than others, which may be a function of the heterogeneity of the parental varieties or the degree of difference between the two parents. Within families that responded to selection for multiple traits, some traits responded more frequently to selection in early generations. This includes traits such as PH that are easy to assess visually when selecting spikes in the field, and those that are not, such as TKW. Other traits may not change in early generations, or may change in the opposite direction of what is desired, such as LLSD. This may mean that for certain traits it is better to wait to conduct selection till later generations, and a potential function of the collaboration with researchers could be to identify which traits respond to selection and which do not, or to identify easy techniques in the field to avoid undesirable changes in the populations. Further analyses will investigate the relation between the parents of the crosses and the response to selection in the $\mathrm{F}_{2}$ progenies.

Results in terms of means and variances for each trait measured for all the Croisements du Roc populations evaluated on their farms were distributed to each farmer, as well as the results from the side-by-side trials of selected and unselected $\mathrm{F}_{3}$ families at Moulon. While there were differences among families tested at the same farm, often with one or two families being identified as very promising by the farmer, farmers and researchers always use more than one year to evaluate the potential of new population varieties and the early-generation cross populations are no exception. The on-farm trials from 2008-2010, in the $\mathrm{F}_{3}-\mathrm{F}_{4}$ generations presented certain difficulties in drawing conclusions across all field sites, because the specific populations grown on each farm were not the same from one farm to the next. This was due to both the limited availability of seed of each family and because families were targeted to the environment where they were most likely to be adapted based on their parentage and the phenotypic evaluation done on one farm in 2008. In addition to the statistical challenges with this trial design, the farmers needed more flexibility in choosing populations to keep and discard. The ideal trial setup from a statistical point of view, with the same populations replicated within and among farms, was not feasible from a practical standpoint.

\subsection{Lessons Learned and Methods Developed for the Future of the Project}

One of the main themes that emerged in discussions among farmers and scientists is the different approaches of farmers and scientists to the selection process and to the evaluation of plant and variety performance. Scientists have a more analytical, quantitative approach, while farmers have an appreciation of the interactions of the plant with its environment and the overall performance of plant populations in their fields. In this case of participatory selection, the goal is to bring together the strengths of both these methods to improve the on-farm selection of populations that respond to the needs of organic farmers. While, in general, scientists have been criticized for being overly reductionist, and farmers have been criticized for being less rigorous in their experiments, in this case participants have an appreciation and respect for the expertise and experience that each person brings to the collective project.

The FSO project was seen by many farmers as too top-down, primarily directed by researchers. In particular, the development of a collaborative project was difficult due to the EU requirements that all project documents and reports be submitted in English, which facilitates international work among scientists but creates barriers to farmer participation in project meetings and written publications. 
Researchers agreed with this assessment in general, as the project was designed to respond to a specific need for information in order to shape the regulatory framework for conservation varieties and was not intended to be a program of participatory plant breeding. The information gained and lessons learned from the FSO project can be used to in collaborative projects, as it helped researchers learn more about farmers evaluation of their varieties and their motivations in cultivating these non-conventional varieties. It is hoped that the results submitted to the European Commission will result in a regulatory framework that is more conducive to on-farm conservation and selection.

The project Croisements $d u$ Roc began as an initiative of farmers within the RSP and has been co-constructed by farmers, the RSP and the research team. The majority of farmers involved in the Croisements $d u$ Roc project also cultivate historic varieties or landraces within the larger RSP association. There is an ongoing discussion on the advantages and disadvantages of making crosses rather than selecting plants within landraces or making mixtures of landraces of interest. This includes questions of which methods of plant breeding are ethically acceptable in organic systems, whether planned crosses have a place in the creation of farmer varieties, and whether this affects the integrity of the plant or variety. Crossing landraces provides more diversity for selection for new conditions, especially when landraces have lost most of their initial diversity through reduction in the land area cultivated or through conservation ex situ in a genebank. This presents an alternative when there is not diversity present in a landrace or when varieties are not working in a mixture. However, the in situ conservation of landraces with on-farm mass selection to improve local adaptation and performance, and the approach of mixing landraces and allowing the mixed population to evolve in situ are also very valuable as methods of introducing diversity and maintaining evolutionary potential. Current studies in parallel to the Croisements $d u$ Roc project are evaluating the longer-term evolution and adaptation of these populations in the farmer network.

\subsection{Structure of Collaborative Bread-Wheat Breeding Project}

The project Croisements $d u$ Roc has evolved into a collaborative plant breeding project with shared responsibility among farmers, farmers' associations and researchers in the context of a new European project that has much more flexibility in terms of the structure of research projects. From the preliminary year of on-farm trials, there appears to be much interest on the part of farmers, but there are also many questions on methodology, ranging from practical to theoretical and ethical. Discussions over methods and strategies have led to a better understanding of the needs and constraints of each partner, and the goal is for the project to remain flexible, within the limits of some minimal standards that all participants agree to implement, with participants able to choose their level of involvement over time. In terms of methods of experimental design, there is always a tension between researchers need for designs that give greater precision and allow for appropriate statistical analysis and farmers need for simplicity in terms of management. This has led researchers to look into alternatives to traditional experimental designs such as randomized complete block designs which may be difficult for farmers without small scale equipment to implement.

A broader reflection on the methods of organization of the on-farm trials to meet both researcher and farmer needs led to the new structure of the trials. To provide greater flexibility for the farmers and accommodate researchers need for quantitative data to analyze population adaptation and evolution, 
a regional platform satellite trial model was implemented in 2010-2011, based on methods developed by Snapp [38]. Figure 4 shows the division of on-farm trials in the French network and Figure 5 is a schematic of the overall organization of the collaborative wheat breeding program.

One farm in each region, preferably with access to small plot equipment, was designated to host the regional platform trial. This trial consisted of about 30 different populations with two checks chosen by the farmers and replicated twice each. Plant phenotypic data is taken to characterize the populations, comparable to data collected in previous years as described in the material and methods section, and agronomic traits such as plot yield and protein are measured. Satellite trials have no restrictions on the number of populations or their consistency from one year to the next, which gives farmers much more flexibility in deciding which populations to try, keep and discard. These satellite trials do not collect quantitative data, but farmers record visual scores at key stages during plant development (winter survival and early spring vigor, heading time, and maturity). Farmers also recorded these observations at the regional platform trials during summer field visits in 2011 and discuss the merits of different populations and breeding objectives. Phenotypic observations include traits of greatest interest to the farmers. Regional associations and the RSP are responsible for the collection of farmer observations on satellite and regional farms and for the coordination and facilitation of project activities.

Figure 4. Map of on-farm collaborative wheat breeding trials in 2010-2011.

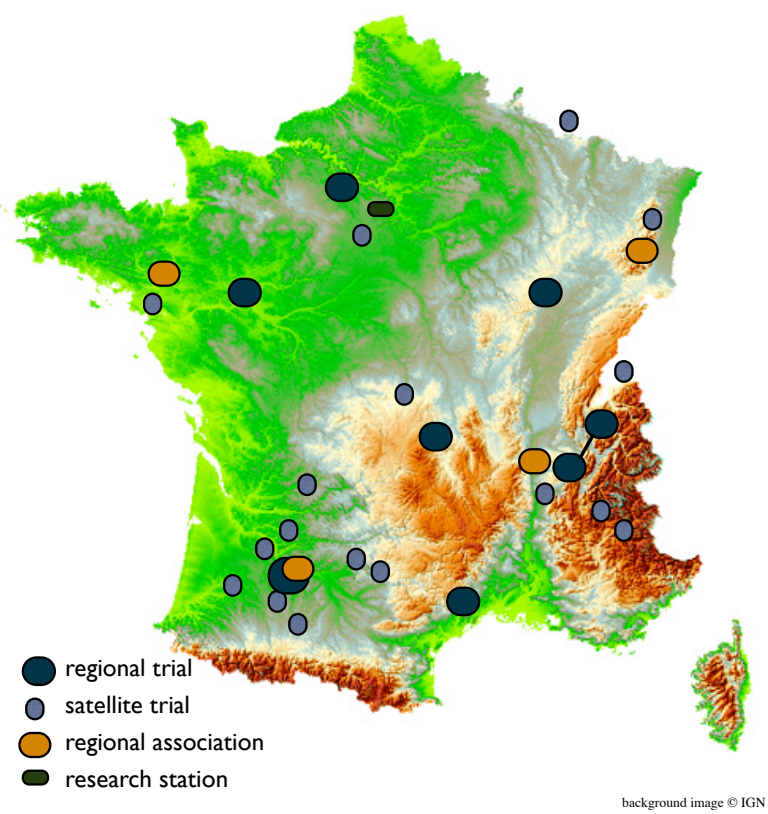

Collaborations with farmer-bakers will be used to assess quality for artisanal breadmaking as soon as sufficient grain is available. It is hoped that this design will enable the network to use data collected on the research platforms to assess the performance of populations on their farms and to choose new populations or parents for crosses that will perform well under each farmers' specific environmental conditions. The role of regional associations and the national RSP must not be underestimated in making this network of trials possible and in organizing field days and farm visits to encourage the exchange of ideas and selected populations among participants. 
Figure 5. Schematic of the organization and components of the French collaborative wheat breeding project.

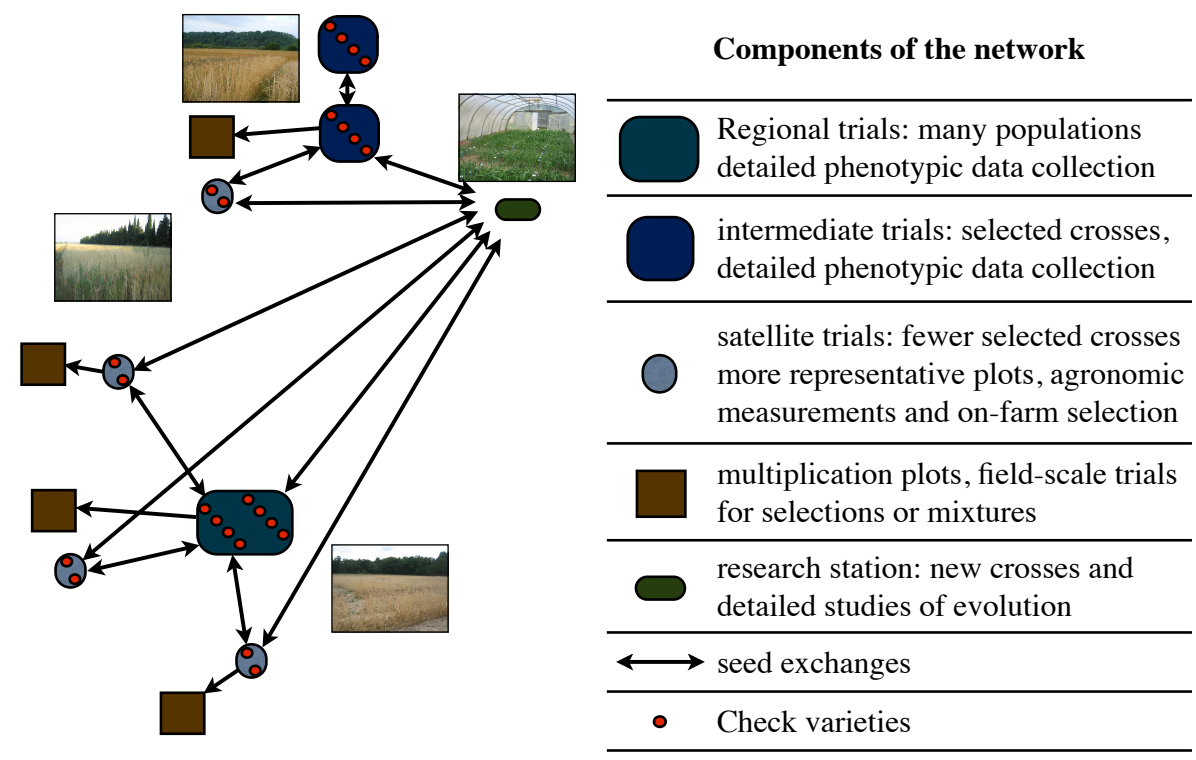

\section{Conclusions}

While farmers may always base their selection, appropriately, on their knowledge of the workings of specific organic agricultural systems and their intuitive assessment of plant global performance on their farms, scientific analysis may be useful for documenting these populations and showing the effectiveness of farmer selection for the conservation and improvement of cultivated populations. A combined approach of evolution under natural selection and directed farmer selection within evolving populations may be useful in developing varieties adapted to organic systems [10]. In fact, certain traits may not be favored by natural selection and may require conscious selection to maintain landrace qualities which is not provided if these varieties are conserved in genebanks.

The value of landraces lies in their history of farmer selection and adaptation to diverse environmental conditions worldwide, their capacity to continually evolve and their resilience to heterogeneous environmental conditions. This creative process of variety development through on-farm selection has largely been lost in industrialized agricultural systems. Collaborative plant breeding in developed countries, starting either with existing landraces or with new populations developed from crosses and farmer-selected variety mixtures can renew this process, reclaiming the knowledge of selection and autonomy of seed production for farming communities. This process of continual crop evolution is key to adapting crops to changing climatic conditions and complex environmental stresses which are present in organic and low-input environmental systems, both in developed and developing countries. On-farm selection by farmers who are also millers and bakers or who work closely with them is also key to developing varieties that have the right characteristics for high quality artisanal breads and regional products.

On-farm selection is thus complementary to on-farm conservation, using the diversity within an existing farmer network to maintain and enhance local adaptation and crop performance. While on-farm selection requires a significant commitment from farmers and researchers to be successful, a relatively 
small group of dedicated farmers and researchers can serve a broader public interest in conserving genetic diversity for important agricultural species through selecting diverse populations across a wide range of environments. These populations, while started by one farmer or the research group, can then be tested and selected in many on-farm environments. The exchange of observations and ideas among participants in the collaborative selection project within the RSP is very rich for both farmers and scientists, highlighting the value of a network approach to plant breeding, rather than an approach were all communication is between individual farmers and the research institution. Because the project was started and driven by farmers, it has far greater durability than a project tied to a particular grant or funding source. By working in this network we hope to increase farmer autonomy in variety creation and to develop a sustainable process of varietal innovation, leading not necessarily to new fixed varieties, but rather to well-adapted heterogeneous populations for each farm which continue to evolve.

\section{Conflict of Interest}

The authors declare no conflict of interest.

\section{Acknowledgements}

Part of the research leading to these results has received funding from the Specific Targeted Research Project of the European Commission 6th Framework Program Priority 8.1 SSP: Opportunities for farm seed conservation, breeding and production Proposal/Contract no.: SSP-CT-2006-04434, and the European Community's Seventh Framework Programme (FP7/ 2007-2013) under the Grant Agreement n245058-Solibam (Strategies for Organic and Low-Input Breeding and Management). JC Dawson was supported by an INRA postdoctoral grant and P Riviere was supported by a doctoral grant from the DIM ASTREA program of the Region Ile de France. The authors would like to thank the following people: Véronique Chable, Jérôme Enjalbert, Nicolas Schermann, Henri Ferté, Giandommenico Cortiana, Thomas Levillain, Silvio Pino, Aart Osman, Elie Guillo and all the farmers involved in the FSO and Croisement du Roc projects.

\section{References}

1. Lammerts van Bueren, E.T.; Backes, G.; Vriend, H.; Ostergaard, H. The role of molecular markers and marker assisted selection in breeding for organic agriculture. Euphytica 2010, 175, 51-64.

2. Löschenberger, F.; Fleck, A.; Grausgruber, H.; Hetzendorfer, H.; Hof, G.; Lafferty, J.; Marn, M.; Neumayer, A.; Pfaffinger, G.; Birschitzky, J. Breeding for organic agriculture: The example of winter wheat in Austria. Euphytica 2008, 163, 469-480.

3. Phillips, S.L.; Wolfe, M.S. Evolutionary plant breeding for low input systems. J. Agric. Sci. 2005, $143,245-254$.

4. Ceccarelli, S. Positive interpretation of genotype by environment interactions in relation to sustainability and biodiversity. In Plant Adaptation and Crop Improvement; Cooper, M., Hammer, G.L., Eds.; CAB International: Wallingford, Oxon, UK, 1996; pp. 467-486. 
5. Demeulenaere, E.; Bonneuil, C.; Balfourier, F.; Basson, A.; Berthellot, J.F.; Chesneau, V.; Ferté, H.; Galic, N.; Kastler, G.; Koenig, J.; et al. Étude des complémentarités entre gestion dynamique à la ferme et gestion statique en collections. em Les Actes du BRG 2008, 7, 117-138.

6. Finckh, M.R.; Gacek, E.S.; Goyeau, H.; Lannou, C.; Merz, U.; Mundt, C.C.; Munk, L.; Nadziak, J.; Newton, A.C.; de Vallavieille-Pope, C.; et al. Cereal variety and species mixtures in practice, with emphasis on disease resistance. Agronomie 2000, 20, 813-837.

7. Hajjar, R.; Jarvis, D.I.; Gemmill-Herren, B. The utility of crop genetic diversity in maintaining ecosystem services. Agric. Ecosyst. Environ. 2008, 123, 261-270.

8. Heal, G.; Walker, B.; Levin, S.; Arrow, K.; Dasgupta, P.; Daily, G.; Ehrlich, P.; Maler, K.G.; Kautsky, N.; Lubchenco, J.; et al. Genetic diversity and interdependent crop choices in agriculture. Resour. Energy Econ. 2004, 26, 175-184.

9. Horneburg, B.; Becker, H.C. Crop adaptation in on-farm management by natural and conscious selection: A case study with lentil. Crop Sci. 2008, 48, 203-212.

10. Murphy, K.M.; Lammer, D.; Lyon, S.R.; Carter, B.; Jones, S.S. Breeding for organic and low-input farming systems: An evolutionary-participatory breeding method for inbred cereal grains. Renewable Agric. Food Syst. 2005, 20, 48-55.

11. Newton, A.C.; Begg, G.S.; Swanston, J.S. Deployment of diversity for enhanced crop function. Ann. Appl. Biol. 2009, 154, 309-322.

12. Zhu, y.; Chen, H.; Fan, J.; Wang, Y.; Li, Y.; Chen, J.; Fan, J.X.; Yang, S.; Hu, L.; Leung, H.; et al. Genetic diversity and disease control in rice. Nature 2000, 406, 718-722.

13. Altieri, M.A. The ecological role of biodiversity in agroecosystems. Agric. Ecosyst. Environ. 1999, 74, 19-31.

14. Ceccarelli, S.; Grando, S. Decentralized participatory plant breeding: An example of demand driven research. Euphytica 2007, 155, 349-360.

15. Desclaux, D. Participatory Plant Breeding Methods for Organic Cereals. In Proceedings of the COST SUSVAR/ECO-PB Workshop on Organic Plant Breeding Strategies and the Use of Molecular Markers, Driebergen, The Netherlands, 17-19 January 2005; Lammerts Van Bueren, E.T., Goldringer, I., Ostergard, H., Eds.; Louis Bolk Institute, Driebergen, The Netherlands, 2005; pp. 17-23.

16. Finckh, M.R. Integration of breeding and technology into diversification strategies for disease control in modern agriculture. Eur. J. Plant Pathol. 2008, 121, 399-409.

17. Østergård, H.; Finckh, M.R.; Fontaine, L.; Goldringer, I.; Hoad, S.P.; Kristensen, K.; Lammerts van Bueren, E.T.; Mascher, F.; Munk, L.; Wolfe, M.S. Time for a shift in crop production: Embracing complexity through diversity at all levels. J. Sci. Food Agric. 2009, 89, 1439-1445.

18. Wolfe, M.S.; Baresel, J.P.; Desclaux, D.; Goldringer, I.; Hoad, S.; Kovacs, G.; Löschenberger, F.; Miedaner, T.; Østergard, H.; Lammerts van Bueren, E.T. Developments in breeding cereals for organic agriculture. Euphytica 2008, 163, 323-346.

19. Sperling, L.; Ashby, J.A.; Smith, M.E.; Weltzien, E.; McGuire, S. A framework for analyzing participatory plant breeding approaches and results. Euphytica 2001, 122, 439-450. 
20. Ceccarelli, S.; Grando, S.; Bailey, E.; Amri, A.; El-Felah, M.; Nassif, F.; Rezgui, S.; Yahyaoui, A. Farmer participation in barley breeding in Syria, Morocco and Tunisia. Euphytica 2001, 122, 521-536.

21. Wolfe, M.S. Crop strength through diversity. Nature 2000, 406, 681-682.

22. Ceccarelli, S. Specific adaptation and breeding for marginal conditions. Euphytica 1994, 77, 205-219.

23. Finckh, M.R.; Wolfe, M.S. Diversification strategies. In The Epidemiology of Plant Disease, 2 ed.; Cooke, B.M., Gareth Jones, D., Kaye, B., Eds.; Springer: Dordrecht, The Netherlands, 2006.

24. Enjalbert, J.; Dawson, J.C.; Paillard, S.; Rhoné, B.; Rousselle, Y.; Thomas, M.; Goldringer, I. Dynamic management of crop diversity: From an experimental approach to on-farm conservation. C. R. Biol. 2011, 334, 458-468.

25. Enjalbert, J.; Goldringer, I.; Paillard, S.; Brabant, P. Molecular markers to study genetic drift and selection in wheat populations. J. Exp. Bot. 1999, 50, 283-290.

26. Goldringer, I.; Enjalbert, J.; David, J.; Paillard, S.; Pham, J.L.; Brabant, P. Dynamic management of genetic resources: A 13 year experiment on wheat. In Broadening the Genetic Base of Crop Production; Cooper, H.D., Spillane, C., Hodgkin, T., Eds.; IPGRI/FAO: Rome, Italy, 2001; pp. 245-260.

27. Lavigne, C.; Reboud, X.; Lefranc, M.; Porcher, E.; Roux, F.; others. Evolution of genetic diversity in metapopulations: Arabidopsis thaliana as an experimental model. Genet. Sel. Evol. 2001, 33, S399-S423.

28. Porcher, E.; Giraud, T.; Goldringer, I.; Lavigne, C. Experimental demonstration of a causal relationship between heterogeneity of selection and genetic differentiation in quantitative traits. Evolution 2004, 58, 1434-1445.

29. Osman, A.; Chable, V. Inventory of initiatives on seeds of landraces in Europe. J. Agric. Environ. Int. Dev. 2009, 103, 95-130.

30. Almekinders, C.J.M.; de Boef, W.; Engels, J. Synthesis between crop conservation and development. In Encouraging Diversity: The Conservation and Development of Plant Genetic Resources; Almekinders, C., de Boef, W., Eds.; Intermediate Technology Publications: London, UK, 2000; pp. 330-338.

31. Berthaud, J.; Clément, J.C.; Empearire, L.; Louette, D.; Pinton, F.; Sanou, J.; Second, G. The role of local level gene flow in enhancing and maintaining genetic diversity. In Broadening the Genetic Base of Crop Production; Cooper, H.D., Spillane, C., Hodgkin, T., Eds.; IPGRI/FAO: Rome, Italy, 2001; pp. 81-103.

32. Elias, M.; McKey, D.; Panaud, O.; Anstett, M.C.; Robert, T. Traditional management of cassava morphological and genetic diversity by the Makushi Amerindians (Guyana, South America): Perspectives for on-farm conservation of crop genetic resources. Euphytica 2001, 120, 143-157.

33. Louette, D.; Charrier, A.; Berthaud, J. In situ conservation of maize in Mexico: Genetic diversity and maize seed management in a traditional community. Econ. Bot. 1997, 51, 20-38.

34. Smith, M.E.; Castillo G., F.; Gomez, F. Participatory plant breeding with maize in Mexico and Honduras. Euphytica 2001, 122, 551-565. 
35. Serpolay, E.; Dawson, J.C.; Chable, V.; Lammerts Van Bueren, E.; Osman, A.; Pino, S.; Silveri, D.; Goldringer, I. Phenotypic responses of wheat landraces, varietal associations and modern varieties when assessed in contrasting organic farming conditions in Western Europe. Org. Agric. 2011, doi 10.1007/s13165-011-00116.

36. Parzies, H.K.; Spoor, W.; Ennos, R.A. Genetic diversity of barley landrace accessions (Hordeum vulgare ssp. vulgare) conserved for different lengths of time in ex situ gene banks. Heredity $\mathbf{2 0 0 0}$, 84, 476-486.

37. Commission, E. Commission Directive 2008/62/EC of 20 June 2008 providing for certain derogations for acceptance of agricultural landraces and varieties which are naturally adapted to the local and regional conditions and threatened by genetic erosion and for marketing of seed and seed potatoes of those landraces and varieties, 2008. Available online: http://eur-lex.europa.eu (accessed on 21 April 2011).

38. Snapp, S.S. Mother and baby trials: A novel trial design being tried out in Malawi. Target Newsletter of the Southern Africa Soil Fertility Network 1999, 17, 8.

(C) 2011 by the authors; licensee MDPI, Basel, Switzerland. This article is an open access article distributed under the terms and conditions of the Creative Commons Attribution license (http://creativecommons.org/licenses/by/3.0/.) 